\title{
TRPM7 Is Essential for RANKL-Induced Osteoclastogenesis
}

\author{
Yu-Mi Yang ${ }^{1}$, Hwi-Hoon Jung ${ }^{2}$, Sung Jun Lee ${ }^{1}$, Hyung-Jun Choi ${ }^{2}$, Min Seuk Kim ${ }^{3, *}$, and Dong Min Shin ${ }^{1, *}$ \\ Departments of ${ }^{1}$ Oral Biology, ${ }^{2}$ Pediatric Dentistry, Yonsei University College of Dentistry, Seoul 120-752, ${ }^{3}$ Department of Oral Physiology, \\ College of Dentistry, Wonkwang University, Iksan 570-749, Korea
}

\begin{abstract}
The transient receptor potential melastatin type 7 (TRPM7) channel is a widely expressed nonselective cation channel with fusion to the C-terminal alpha kinase domain and regarded as a key regulator of whole body $\mathrm{Mg}^{2+}$ homeostasis in mammals. However, the roles of TRPM7 during osteoclastogenesis in RAW264.7 cells and bone marrow-derived monocyte/macrophage precursor cells (BMMs) are not clear. In the present study, we investigate the roles of TRPM 7 in osteoclastogenesis using methods of small interfering RNA (siRNA), RT-PCR, patch-clamp, and calcium imaging. RANKL (receptor activator of NF- $\kappa$ B ligand) stimulation did not affect the TRPM7 expression and TRPM 7-mediated current was activated in HEK293, RAW 264.7, and BMM cells by the regulation of $\mathrm{Mg}^{2+}$. Knock-down of TRPM 7 by siTRPM 7 reduced intracellular $\mathrm{Ca}^{2+}$ concentration $\left(\left[\mathrm{Ca}^{2+}\right]_{\mathrm{i}}\right)$ increases by $0 \mathrm{mM}\left[\mathrm{Mg}^{2+}\right]_{\mathrm{e}}$ in $\mathrm{HEK} 293$ cells and inhibited the generation of RANKL-induced $\mathrm{Ca}^{2+}$ oscillations in RAW 264.7 cells. Finally, knock-down of TRPM7 suppressed RANKL-mediated osteoclastogenesis such as activation and translocation of NFATc1, formation of multinucleated cells, and the bone resorptive activity, sequentially. These results suggest that TRPM7 plays an essential role in the RANKL-induced $\left[\mathrm{Ca}^{2+}\right]_{i}$ oscillations that triggers the late stages of osteoclastogenesis.
\end{abstract}

Key Words: Calcium signaling, Osteoclastogenesis, RANKL, TRPM7

\section{INTRODUCTION}

Calcium $\left(\mathrm{Ca}^{2+}\right)$ plays a critical role in many cellular processes from differentiation to death in cells. $\mathrm{Ca}^{2+}$ entry into cells mediates by store-operated $\mathrm{Ca}^{2+}$ channels (SOCs) and transient receptor potential (TRP) channels [1]. TRP channels have been proposed to operate as SOCs. TRP channels consist of six transmembrane spanning domains (S1-6) with a pore-forming loop between $\mathrm{S} 5$ and $\mathrm{S} 6$, and include intracellular N- and C-terminal regions. According to the degree of amino acid homology, the TRP family can be subdivided into seven subgroups (TRPC, TRPV, TRPM, TRPA, TRPP, TRPML, and TRPN). TRPM (M stands for "melastin") belongs to super-family of TRP channels, which consist of eight different isoforms, TRPM1-TRPM8 [2]. Apart from other TRP channels, the distinct characteristic of TRPM does not contain $\mathrm{N}$-terminal ankyrin repeat motifs but con-

Received October 31, 2012, Revised December 11, 2012,

Accepted January 20, 2013

Corresponding to: Min Seuk Kim, Department of Oral Physiology, College of Dentistry, Wonkwang University, 460, Iksandae-ro, Iksan 570-749, Korea. (Tel) 82-63-850-6997, (Fax) 82-63-850-7313, (E-mail) happy1487@wku.ac.kr, Dong Min Shin, Department of Oral Biology, Yonsei University College of Dentistry, 50, Yonsei-ro, Seodaemon-gu, Seoul 120-752, Korea. (Tel) 82-2-2228-3051, (Fax) 82-2-364-1085, (E-mail)dmshin@yuhs.ac This is an Open Access article distributed under the terms of the
Creative Commons Attribution Non-Commercial License (http:// Creative Commons Attribution Non-Commercial License (http:// use, distribution, and reproduction in any medium, provided the original work is properly cited. tain functional proteins in C-termini. TRPM7, for example, contain functional $\alpha$-kinase segments, a type of serine/threonine-specific protein kinase $[3,4]$ that is essential for modulating channel activity [5,6]. Due to its structural features, TRPM7 is considered as both a kinase, which is capable of phosphorylating itself and other substrates, and a cation channel, which conducts cations (highly permeable to $\mathrm{Ca}^{2+}$ and $\mathrm{Mg}^{2+}$ ) into the cell [7]. TRPM7, as a cation channel, is constitutively opened and mediates capacitative $\mathrm{Ca}^{2+}$ entry, which is tightly regulated by intracellular $\mathrm{Mg}^{2+}$ concentration such as Mg-ATP and other Mg-nucleotides [8].

RANKL (receptor activator of nuclear factor- $\kappa$ B ligand) is expressed in osteoblastic/stromal cells and is critical importance for osteoclast differentiation. In our previous works, it has been reported that RANKL-induced oscillations by intracellular $\mathrm{Ca}^{2+}$ concentration $\left(\left[\mathrm{Ca}^{2+}\right]_{\mathrm{i}}\right)$ increases are related with the extracellular $\mathrm{Ca}^{2+}$ influx through SERCA (sarco/ endoplasmic reticulum $\mathrm{Ca}^{2+}$ ATPase) and SOCs, and intracellular ROS (reactive oxygen species) increases [9,10]. Extracellular $\mathrm{Ca}^{2+}$ influx for maintaining $\left[\mathrm{Ca}^{2+}\right]_{\mathrm{i}}$ oscillations trigger the late stage in osteoclast differentiation [11]. However, $\mathrm{Ca}^{2+}$ entry pathway via the plasma membrane in osteoclastogenesis is not clearly known. The activity of TRPM7, as a $\mathrm{Ca}^{2+}$ permeable cation channel, is indispensable part of maintaining cell homeostasis including cell growth, proliferation and differentiation [4]. TRPM7 also can be activated by $\mathrm{ROS}$ and regulated intracellular $\mathrm{Mg}^{2+}$ level

ABBREVIATIONS: RANKL, receptor activator of NF- $\kappa$ B ligand; TRP, transient receptor potential; SOCs, store-operated $\mathrm{Ca}^{2+}$ channels; $\left[\mathrm{Ca}^{2+}\right]_{\mathrm{i}}$, intracellular $\mathrm{Ca}^{2+}$ concentration; ROS, reactive oxygen species; MNCs, multi-nucleated cells. 
$[12,13]$. It was suggested that TRPM7 can serve as a $\mathrm{Ca}^{2+}$ permeable cation channel in osteoclasts and regulate the activity of the RANKL-induced $\mathrm{Ca}^{2+}$ oscillations and osteoclastogenesis.

In this study, we aimed to investigate the involvement of TRPM7 in RANKL-induced $\mathrm{Ca}^{2+}$ oscillations as a $\mathrm{Ca}^{2+}$ permeable channel and the role in physiological activities of osteoclasts.

\section{METHODS}

\section{Cell culture and reagents}

RAW264.7 (Korean Cell Line Bank, South Korea) and primary cultured BMMs were maintained in Dulbecco's modified Eagle's medium (DMEM, Invitrogen, Carlsbad, CA, USA) and minimum essential medium alpha ( $\alpha$-MEM) supplemented with $10 \%$ fetal bovine serum (FBS, Invitrogen) and incubated in $5 \% \mathrm{CO}_{2}$ incubator. M-CSF and RANKL were treated at $50 \mathrm{ng} / \mathrm{ml}$ concentration in $\alpha$-MEM. RANKL and M-CSF were purchased from KOMA Biotech (Seoul, Korea). HEK293 cells were cultured in DMEM containing 10\% FBS, and $100 \mathrm{units} / \mathrm{ml}$ penicillin and streptomycin. Fura-2/AM was purchased from Teflabs (Austin, TX, USA). Gadolinium chloride $\left(\mathrm{Gd}^{3+}\right)$ and adenosine triphosphate (ATP) were from Sigma Aldrich (St Louis, MO, USA). Monoclonal antibody (mAbs) for NFATc1 and polyclonal antibody for TRPM7 were obtained from Santa Cruz Biotechnology (Santa Cruz, CA, USA).

\section{Preparation of BMMs}

The femur and tibia were isolated from $4 \sim 6$ weeks old mice as described previously [14]. Whole cells derived from bone marrow of femur and tibia was collected and cultured in $\alpha$-MEM medium containing $10 \% \mathrm{FBS}$ and $10 \mathrm{ng} / \mathrm{ml}$ M-CSF. The following day, non-adherent cells in media were collected and seeded on adequate plates and treated with M-CSF (50 ng/ml). After 2 days non-adherent cells were washed out and adherent cells were used as BMMs.

\section{RT-PCR (reverse transcription polymerase chain reaction)}

Total RNA was isolated from each cell using Trizol reagents (Invitrogen). Total isolated RNA was amplified according to the manufature's protocol using AccuPower ${ }^{\mathbb{R}}$ RT PreMix (BIONEER, Daejeon, Korea). cDNA was amplified by PCR with $\mathrm{HiPi}^{\mathrm{TM}}$ Thermostable DNA polymerase (Elpis, Seoul, Korea). The primer sequences of genes were as follows: TRPM7 (531 bp), 5'-AGG AGA ATG TCC CAG AAA TCC-3' (forward) and 5'-TCC TCC AGT TAA AAT CCA AGC-3' (reverse); $\beta$-actin (514 bp), 5'-TGT GAT GGT GGG AAT GGG TCA G-3' (forward) and 5'-TTT GAT GTC ACG CAC GAT TTC C-3' (reverse).

\section{siRNA transfection}

Small interfering (si) RNA for TRPM7, sense (5'-ACC GAG CTG GTC GCA CAA TTA TTT CAA GAG AAT AAT TGT GCG ACC AGC TCT TTT TC-3') and anti-sense (5'-TGC AGA AAA AGA GCT GGT CGC ACA ATT ATT CTC TTG AAA TAA TTG TGC GAC CAG CT-3'), was annealed with T4 DNA ligase and inserted into $50 \mathrm{ng} / \mu \mathrm{l} \mathrm{psi-}$ STRIKE vector (Promega Corporation, Madison, WI, USA) by following the manufacture's procedure. Cells were seeded on $35 \mathrm{~mm}$ dish at a density of $1 \sim 5 \times 10^{5}$ cells in antibiotics free media. After $24 \mathrm{~h}$, cells were re-plated in adequate dish. Each plasmid and Lipofectamine 2000 (Invitrogen) was diluted in $250 \mu$ l Opti-MEM respectively and then mixed. The mixture was incubated for $20 \mathrm{~min}$ at room temperature before adding the cell media. Cells were assorted with pEGFP expression.

\section{Western blot}

Whole cell lysates were prepared using RIPA lysis buffer (20 mM Tris, $\mathrm{pH} 7.4,250 \mathrm{mM} \mathrm{NaCl}, 2 \mathrm{mM}$ EDTA, pH 8.0, $0.1 \%$ Triton- $\times 100,0.01 \mathrm{mg} / \mathrm{ml}$ aprotinin, $5 \mu \mathrm{g} / \mathrm{ml}$ leupeptin, $0.4 \mathrm{mM}$ PMSF, and $4 \mathrm{mM} \mathrm{NaVO}$ ), and then spun at 12,000 rpm for $10 \mathrm{~min}$ to remove insoluble material. Proteins (50 $100 \mu \mathrm{g} /$ well) were subjected to $6 \sim 12 \%$ SDS-PAGE respectively, and then were separated by size. Separated proteins were electro-transferred to a nitrocellulose membrane, blocked with $6 \%$ skimmed milk, and probed with Abs against TRPM7 (1:1,000) and NFATc1 (1:3,000). Thereafter, blots were washed, exposed to horseradish peroxidase-conjugated secondary antibodies for $1 \mathrm{~h}$, and finally detected by chemiluminescence (Amersham Pharmacia Biotech, Alington Heights, IL, USA).

\section{$\left[\mathrm{Ca}^{2+}\right]_{i}$ measurement}

Cells were seeded on cover glass in 35 -mm dishes $\left(5 \times 10^{4}\right.$ cells). After $24 \mathrm{~h}$, cells were stimulated with RANKL (50 $\mathrm{ng} / \mathrm{ml}$ ) for indicated time. Cells in physiological salt solution $(140 \mathrm{mM} \mathrm{NaCl}, 5 \mathrm{mM} \mathrm{KCl}, 1 \mathrm{mM} \mathrm{MgCl}, 1 \mathrm{mM} \mathrm{CaCl}, 10$ $\mathrm{mM}$ HEPES, $10 \mathrm{mM}$ glucose, $310 \mathrm{mOsm}, \mathrm{pH}$ 7.4) were incubated with $5 \mu \mathrm{M}$ Fura-2/AM $0.05 \%$ Pluronic F-127 for $30 \mathrm{~min}$ at room temperature and washed out with bath solution. The adherent cells on cover glass were placed on the bottom of a perfusion chamber, and bath solution was perfused continuously. Fura-2 fluorescence intensity was measured using excitation wave lengths of 340 and $380 \mathrm{~nm}$, and emitted fluorescence $510 \mathrm{~nm}$ (Ratio $=\mathrm{F}_{340} / \mathrm{F}_{380}$ ) was collected and monitored at $2 \mathrm{~s}$ intervals using a CCD camera (Universal Imaging Co., Downingtown, PA, USA) as described previously [15]. Images were digitized and analyzed through MetaFluor software (Universal Imaging).

\section{Electrophysiology}

Whole-cell voltage-clamp recordings were made using the perforated patch-clamp method at room temperature. Currents were recorded using a MultiClamp 700B amplifier (Axon Instruments, Union City, CA, USA), subsequently digitized with a sampling rate of $10 \mathrm{kHz}$, and analyzed using pCLAMP10 software (Axon Instruments). The pipette resistance varied between $3 \sim 5 \mathrm{M} \Omega$. Whole-cell currents were elicited by voltage ramps from $-100 \mathrm{mV}$ to $+100 \mathrm{mV}$ (50-ms duration) applied every $2 \mathrm{~s}$ from a holding potential of $0 \mathrm{mV}$. Pipettes for recordings of TRPM7 currents were filled with an internal solution containing (in $\mathrm{mM}$ ): 140 $\mathrm{CsCl}, 8 \mathrm{NaCl}, 10$ EGTA, 10 HEPES, adjusted to $\mathrm{pH} 7.2$ with $\mathrm{CsOH}$ [16]. Nystatin was diluted to a final concentration of $250 \mu \mathrm{g} / \mathrm{ml}$ in the internal solution. The external solution containing (in $\mathrm{mM}$ ): $140 \mathrm{NaCl}, 3 \mathrm{KCl}, 1 \mathrm{CaCl}_{2}, 2$ $\mathrm{MgCl}_{2}, 10 \mathrm{HEPES}, 10$ glucose, adjusted to $\mathrm{pH} 7.2$ with $\mathrm{NaOH}$, and the external solution was replaced by $3 \mathrm{mM}$ 
$\mathrm{CaCl}_{2}$ to change a $\mathrm{Mg}^{2+}$-free external solution.

\section{Immunocytochemistry}

Cells were seeded on coverslips $(22 \times 22)$ and treated with $50 \mathrm{ng} / \mathrm{ml}$ RANKL for $48 \mathrm{~h}$. After fixation in $4 \%$ paraformaldehyde (PFA) for $5 \mathrm{~min}$, cells were sequentially incubated in blocking solution $(0.1 \%$ gelatin, $1 \%$ BSA, $0.01 \%$ sodium azide, $5 \%$ goat serum) for $30 \mathrm{~min}$, overnight in blocking solution containing Abs against NFATc1 (1: 100), and finally were treated with Alexa 488-labeled anti-mouse IgG antibody (Molecular Probes) in blocking solution for $1 \mathrm{~h}$. Nuclei was separately stained with DAPI.

\section{TRAP staining}

The method of TRAP staining has been detailed previously [10]. Briefly, cells were seeded on 48 well-plate at a density of $2 \times 10^{4}$ cells/well and cultured in $\alpha$-MEM containing $10 \%$ FBS with $50 \mathrm{ng} / \mathrm{ml}$ RANKL and M-CSF. After 6 days, TRAP (tartrate-resistant acid phosphatase) staining was performed to determine the extent of differentiation. Cytochemical staining of $\mathrm{TRAP}^{+}$cells were performed using the Leukocyte Acid Phosphate Assay Kit (Sigma Aldrich) by following the manufacturer's procedure. TRAP ${ }^{+}$multinucleated cells (MNCs, $\geq 3$ nuclei) were counted.

\section{Pit assay}

Cells were seeded on bone-slice covered plates (OAAS) and maintained with $50 \mathrm{ng} / \mathrm{ml}$ M-CSF and sRANKL for 15 days. After that, cells were washed with sodium hypochlorite solution for $1 \mathrm{~h}$ at room temperature. Bone slices were imaged, and pits were calculated using MetaMorph software (Molecular Devices).

\section{Statistics}

All data were expressed as the mean \pm SEM. Statistical significance was determined by using a paired or unpaired Student's $t$-test. Statistical significance was set at $\mathrm{p}<0.05$ level.

\section{RESULTS}

\section{Expression and actions of endogenous TRPM7 channels}

TRPM7 has been identified as spontaneously activated $\mathrm{Ca}^{2+}$ - and $\mathrm{Mg}^{2+}$-entry channels and plays a key role for osteoblasts proliferation [17]. In this study, we first examined whether RANKL stimulation affects on the expression of TRPM7. In order to confirm the expression of TRPM7, RANKL was respectively treated for 6 days that is predicted time to be differentiated into osteoclast. As shown in Fig. 1A, the expression of TRPM7 in RAW264.7 cells was not altered in the presence of RANKL. mRNA expressions of TRPM7 were reduced in siTRPM7-tranfected cells (Fig. 1B). In whole-cell patch-clamp experiments, the removal of $\mathrm{Mg}^{2+}$ in extracellular solutions led to activation of TRPM7-

A

B
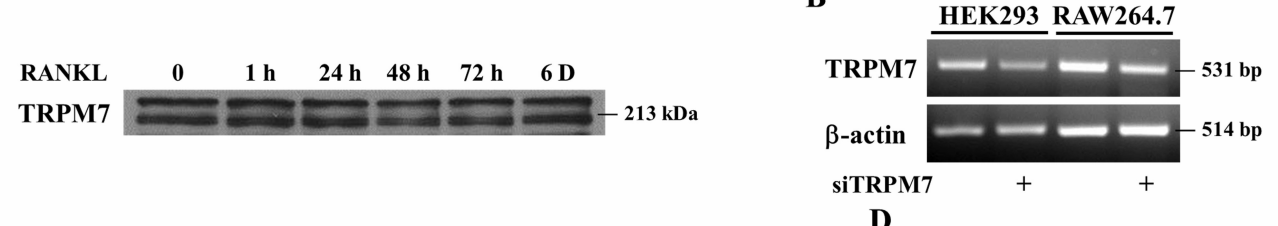

C

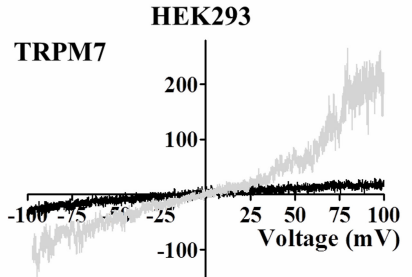

Current (pA)

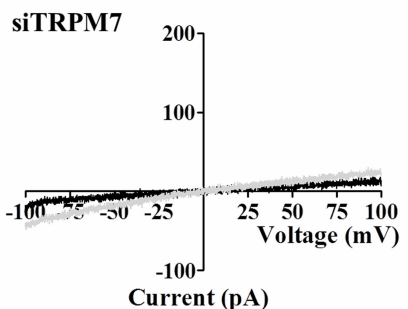

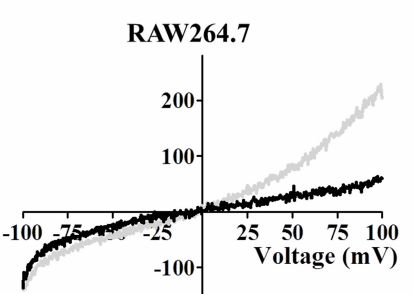

Current (pA)

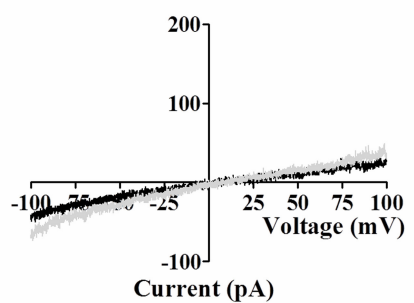

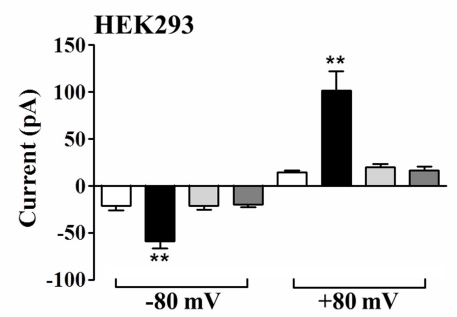

RAW264.7

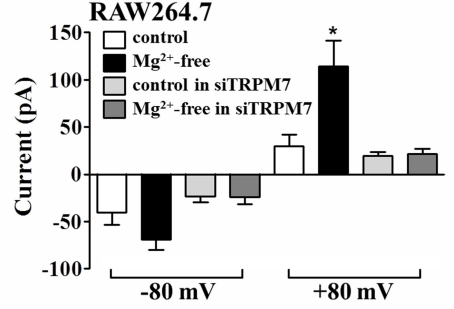

Fig. 1. Expression of and activation of endogenous TRPM7 channels in HEK293, RAW264.7, and BMMs. (A) Whole cells lysates were collected from cells stimulated with RANKL for indicated time. TRPM7 was blotted with its antibody. (B) mRNA expression of TRPM7 were decreased after transfection of siTRPM7 in HEK293 and RAW264.7 cells. (C) Activation of endogenous TRPM7-mediated currents by a voltage ramp $\left(-100 \mathrm{mV}\right.$ to $+100 \mathrm{mV}$ in 50-ms intervals, $\left.\mathrm{V}_{\mathrm{h}}=0 \mathrm{mV}\right)$, used to determine current-voltage relations in cells. TRPM7 currents were activated by $0 \mathrm{mM}\left[\mathrm{Mg}^{2+}\right]_{\mathrm{e}}$ and these effects diminished in TRPM7 knock-down cells. (D) The amplitude of endogenous TRPM7-mediated currents at -80 and $+80 \mathrm{mV}$ in HEK293 and RAW264.7 cells. Data were expressed as the mean \pm SEM. ${ }^{* *} \mathrm{p}<0.01,{ }^{*} \mathrm{p}<0.05$ compared with control. 
mediated currents that exhibit a highly nonlinear current-voltage (I-V) relationship with noticeable outward rectification at positive potentials in eGFP-transfected cells but not showed these effects in siTRPM7-transfected cells (Fig. 1C and 1D). A strongly outward-rectifying I-V relationship of TRPM7 is very similar features to other previous reports and these results show that TRPM7 is expressed regardless of RANKL stimulation and activated by low- $\mathrm{Mg}^{2+}$ concentration $[14,15,18]$.

\section{Effects of deletion of TRPM7 on RANKL-induced $\mathrm{Ca}^{2+}$ signaling}

RANKL-induced $\mathrm{Ca}^{2+}$ increase, which is composed of inernal $\mathrm{Ca}^{2+}$ release and extracellular $\mathrm{Ca}^{2+}$ influx, is essential step for triggering late-stage of osteoclastogenesis by activating NFATc1 $[9,10]$. To confirm whether TRPM7 is involved in the induction of RANKL-induced $\mathrm{Ca}^{2+}$ oscillations as a $\mathrm{Ca}^{2+}$ permeable channel, we examined the effects of deletion of TRPM7 on $\mathrm{Ca}^{2+}$ responses in the presence or absence of RANKL. Reduced mRNA expression of TRPM7 by siTRPM7 treatment (Fig. 2A) resulted in disappearance of $\mathrm{Ca}^{2+}$ oscil-
A

RAW264.7

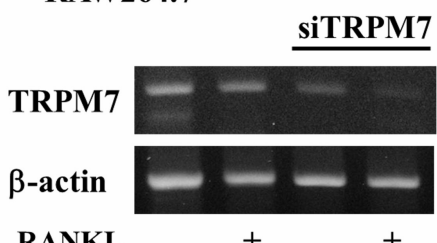

C

HEK293
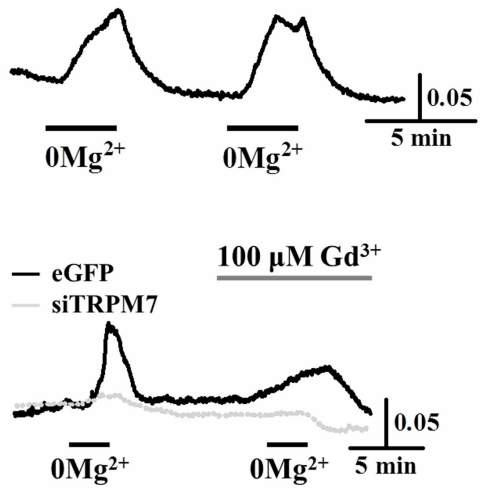

$\mathbf{E}$

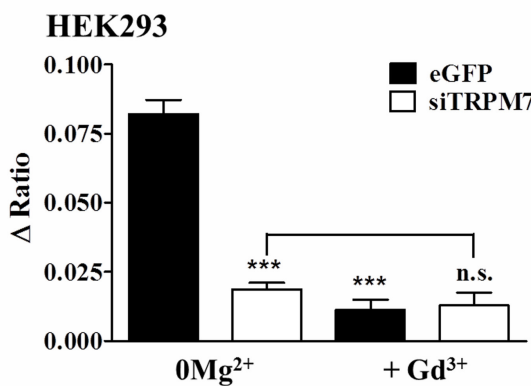

B

RANKL 48 hrs control

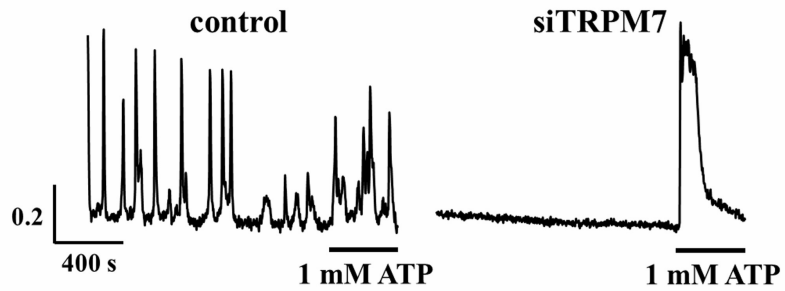

D

$$
\begin{gathered}
\text { RAW264.7 } \\
- \text { eGFP } \\
- \text { siTRPM7 } 7
\end{gathered}
$$

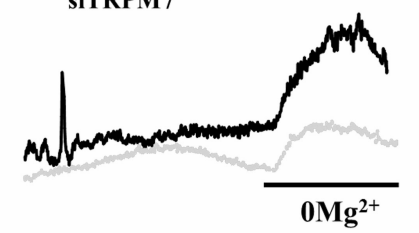

RANKL 48 hrs

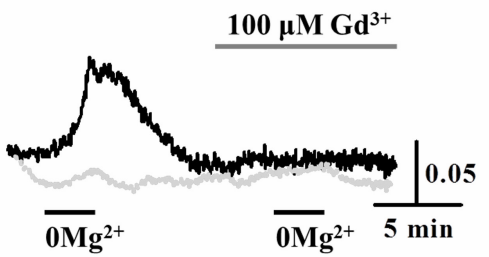

RAW264.7

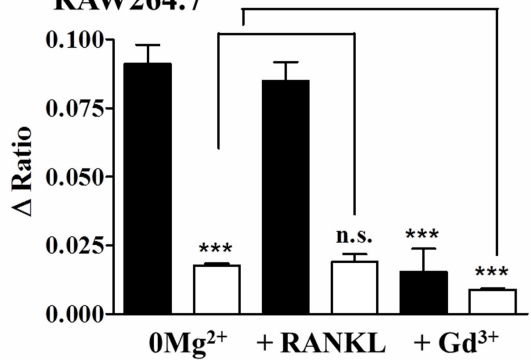

Fig. 2. Effects of deletion of TRPM7 on $\left[\mathrm{Ca}^{2+}\right]_{\mathrm{i}}$ increases mediated by RANKL stimulation and removal of extracellular $\mathrm{Mg}^{2+}$. (A) Cells were transfected with siTRPM7 using lipofectamine 2000. After $72 \mathrm{~h}$ of transfection, whole mRNA was collected using Trizol method. Beta-actin is used as loading control. (B) Control and siTRPM7 treated cells were treated with RANKL. After $48 \mathrm{~h}$ of RANKL stimulation, [Ca $\left.{ }^{2+}\right]_{i}$ in single cell was measured using Fura-2 fluorescence dye. To confirm cell's viability, $1 \mathrm{mM}$ ATP was used. (C) Application of 0 mM $\left[\mathrm{Mg}^{2+}\right]_{\mathrm{e}}$ induced $\left[\mathrm{Ca}^{2+}\right]_{\mathrm{i}}$ increases and it was repeated by the second application of $0 \mathrm{mM}\left[\mathrm{Mg}^{2+}\right]_{\mathrm{e}}$ in HEK293 cells. [Ca $\left.{ }^{2+}\right]_{\mathrm{i}}$ increases also inhibited by $100 \mu \mathrm{M}$ $\mathrm{Gd}^{3+}$ and transfected siTRPM7. (D) Application of $0 \mathrm{mM}\left[\mathrm{Mg}^{2+}\right]_{\mathrm{e}}$ induced $\left[\mathrm{Ca}^{2+}\right]_{\mathrm{i}}$ increases in the absence or presence of RANKL and it was inhibited by $100 \mu \mathrm{M} \mathrm{Gd}^{3+}$ and transfected siTRPM7 in RAW264.7 cells. (E) The degree of $\left[\mathrm{Ca}^{2+}\right]_{\mathrm{i}}$ increases by $\left.0 \mathrm{mM}^{2} \mathrm{Mg}^{2+}\right]_{\mathrm{e}}$ in HEK293 and RAW264.7 cells. Data were expressed as the mean \pm SEM. ${ }^{* * *} \mathrm{p}<0.001$ compared with $0 \mathrm{mM}^{2}\left[\mathrm{Mg}^{2+}\right]_{\mathrm{e}}$ treated control. n.s., not significant. 
lations in response to RANKL stimulation (Fig. 2B), which indicates that activation of TRPM7 is related with the induction of $\mathrm{Ca}^{2+}$ oscillations in osteoclastogenesis. We also observed that siTRPM7 inhibited $\mathrm{Ca}^{2+}$ signaling by $0 \mathrm{mM}$ $\left[\mathrm{Mg}^{2+}\right]_{\mathrm{e}}$ in the presence or absence of RANKL of RAW264.7 cells (Fig. 2D and 2E). The generation of $\mathrm{Ca}^{2+}$ oscillations are related with $\mathrm{Ca}^{2+}$ entry and $\mathrm{Ca}^{2+}$ release from intracellular $\mathrm{IP}_{3}$-sensitive $\mathrm{Ca}^{2+}$ stores, and $\mathrm{Ca}^{2+}$ entry is mediated through the $\mathrm{Mg}^{2+}$-sensitive pathway in polarized cells $[19,20]$. In HEK293 cells, $\mathrm{Ca}^{2+}$ signaling by $0 \mathrm{mM}\left[\mathrm{Mg}^{2+}\right]_{\mathrm{e}}$ was completely blocked by $100 \mu \mathrm{M} \mathrm{Gd}^{3+}$, a known blocker of $\mathrm{Ca}^{2+}$ release activated $\mathrm{Ca}^{2+}$ entry (Fig. $2 \mathrm{C}$ and $2 \mathrm{E}$ ). Interestingly, the $\left[\mathrm{Ca}^{2+}\right]_{\mathrm{i}}$ increases by $\mathrm{Mg}^{2+}$ free solution were not observed in TRPM7 knock-down cells. These results suggest that TRPM7 is playing an essential role in RANKL-induced $\mathrm{Ca}^{2+}$ oscillations as mediating an extracellular $\mathrm{Ca}^{2+}$ entry which is regulated through the $\mathrm{Mg}^{2+}$-sensitive pathway.

\section{Effects of deletion of TRPM7 in late-stage of osteoclas- togenesis}

It has been known that RANKL-induced $\mathrm{Ca}^{2+}$ oscillations is a key factor to determine the late-stage of osteoclastogenesis by sequentially activating calmodulin, calcineurin, and NFATc1 [11]. Activated NFATc1 gets translocated into
$\mathbf{A}$

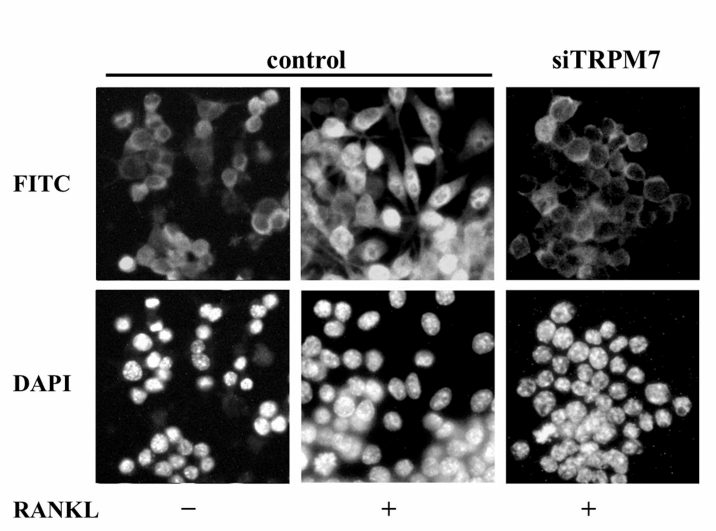

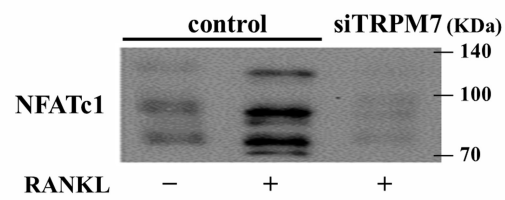

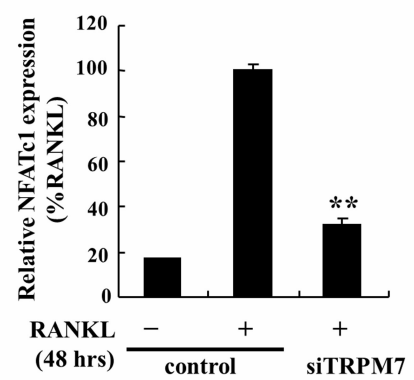

D

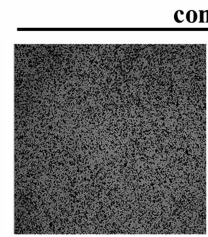

control

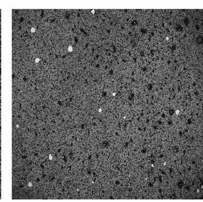

$+$
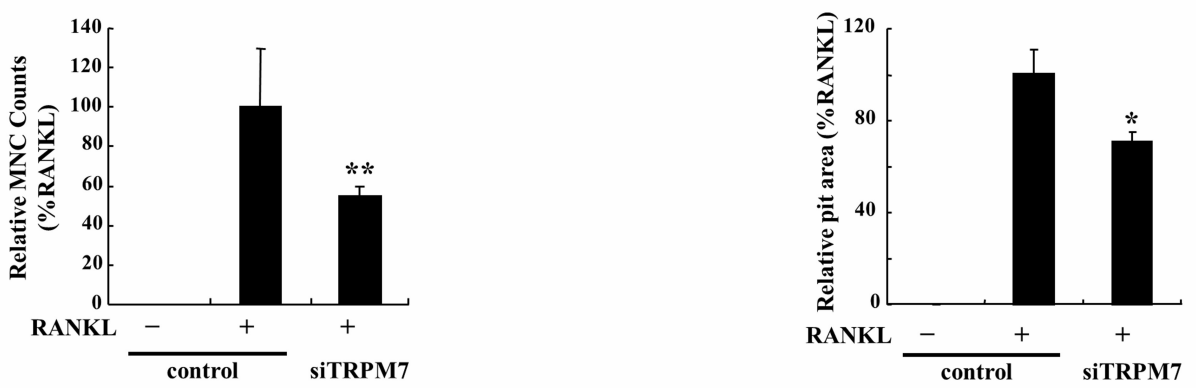

Fig. 3. Effects of deletion of TRPM7 on NFATc1 and bone resorptive activity. (A and B) Cells were transfected with sicontrol and siTRPM7 in the presence or absence of RANKL for $48 \mathrm{~h}$. To confirm the localization and expression of NFATc1, cells were fixed with $4 \%$ paraformaldehyde (PFA) and whole lysates were collected using RIPA lysis buffer respectively. Localization inside the cell and NFATc1 expression in whole lysates was confirmed with antibody for NFATc1. (C) To verify the formation of MNCs, each sample was incubated for 6 days in the presence of RANKL. TRAP staining was performed as described in methods. And then MNCs in each well was counted. (D) To determine the bone resorptive activity, cells were seeded on bone-slice covered plate in the presence of RANKL for 15 days. After incubation, whole image of each well was taken to calculate mineralized area as described in methods. Data were normalized to the expression level in RANKL treated control and expressed as the mean \pm SEM. ${ }^{* *} \mathrm{p}<0.01,{ }^{*} \mathrm{p}<0.05$ compared with RANKL treated control. 
the nucleus and function as a transcription factor, which induces the expression of proteins such as TRAP, Src kinase, INF- $\gamma$, calcitonin, etc [21]. Over these series of protein expression, precursor cells get fused into MNCs, which have abilities of mineralizing the bone. According to previous results, we hypothesized that abolished $\mathrm{Ca}^{2+}$ oscillations by deletion of TRPM7 would affect on the activities of bone resorption. To confirm our hypothesis, the expression and translocation of NFATc1 in response to deletion of TRPM7 was examined in RAW264.7 cells and BMMs. As a result, lack of TRPM7 diminished RANKL-induced NFATc1 translocation into nucleus and reduced NFATc1 expression by $60 \%$ in RAW264.7 cells (Fig. 3A) and BMMs (Fig. 3B). Furthermore, deletion of TRPM7 significantly reduced RANKL-induced responses, formation of MNCs in BMMs (Fig. 3C) and bone resorptive activity in RAW264.7 cells (Fig. 3D). Taken together, these results suggest that abolished $\mathrm{Ca}^{2+}$ oscillations by deletion of TRPM7 affected on NFATc1 activities, fusion into MNCs, and bone resorption.

\section{DISCUSSION}

As tools for communication, intracellular $\mathrm{Ca}^{2+}$ concentration determine various cellular responses such as proliferation, movement, differentiation, etc [1]. Two separated $\mathrm{Ca}^{2+}$ sources, internal and external $\mathrm{Ca}^{2+}$ sources, are virtually being used for triggering and maintaining all the $\mathrm{Ca}^{2+}$ responses including osteoclastogenesis. The property as a $\mathrm{Ca}^{2+}$ conducting channels raised the possibility that TRPM7 may be involved in osteoclastogenesis, based on the requirement for $\mathrm{Ca}^{2+}$ responses. In present study, we examined the potential use of TRPM7 in modulating the bone resorptive activities of osteoclast. The first finding of this study is that TRPM7 is being expressed in osteoclast precursor cells and the constitutive activities are being negatively regulated by intracellular $\mathrm{Mg}^{2+}$ concentration. In osteoclastogenesis, precursor cells present long-lasting $\mathrm{Ca}^{2+}$ oscillations in response to RANKL stimulation. Signals leading differentiation clearly require sustained extracellular $\mathrm{Ca}^{2+}$ influx through certain $\mathrm{Ca}^{2+}$ permeable channels. Hence, our result suggests that TRPM7 must be considered as a candidate for mediating the long-lasting $\mathrm{Ca}^{2+}$ oscillations. Notably, RANKL-induced $\mathrm{Ca}^{2+}$ oscillations and extracellular $\mathrm{Ca}^{2+}$ influx mediated by reduction of intracellular $\mathrm{Mg}^{2+}$ concentration were completely diminished by deletion of TRPM7. In our previous work, ROS, which is generated by RANKL stimulations, induce $\mathrm{Ca}^{2+}$ oscillations through activating the enzymatic reaction such as PLC [9,22]. Based on its characteristics as a kinase and channel, our results strongly suggest that function of TRPM7 as a kinase and cation channel is tightly linked with RANKL-induced ROS generation. Taken together, constitutive expression of TRPM7 would help precursor cells immediately sense the ROS generation and then ROS mediated activation of TRPM7 contributes the induction of $\mathrm{Ca}^{2+}$ oscillations by allowing extracellular $\mathrm{Ca}^{2+}$ influx. In terms of $\mathrm{Mg}^{2+}$ homeostasis in blood plasma, it is well established that bone is also considered as $\mathrm{Mg}^{2+}$ store in a body. Negative regulation of TRPM7 by $\mathrm{Mg}^{2+}$ concentration may explain the regulation of osteoclast activation. Our present study strongly proposes that $\mathrm{Mg}^{2+}$ concentration in blood plasma is one of determinants for osteoclast activity by modulating the TRPM7 conductance.

It has been reported that NFATc1 expression is enhanced in response to RANKL stimulation at transcriptional level.
Considering our main focus of this study, which is on identifying the possibility as a candidate for modulating the bone metabolism, we investigated the effects of deletion of TRPM7 on late-stage of osteoclastogenesis like forming MNCs and bone resorption. Only if TRPM7 has roles in a process of being differentiated into fully-activated osteoclasts, we may use it as a target molecule to treat bone diseases. Our results indicate that extracellular $\mathrm{Ca}^{2+}$ influx through TRPM7 is regarded as a nodal point which sequentially regulates in the activity of NFATc1, forming MNCs, and physiological activity of osteoclasts. These findings address missing links between generation of ROS and induction of $\mathrm{Ca}^{2+}$ oscillations, which are required for triggering late-stage of osteoclastogenesis. TRPM7, which is activated by sensing both intracellular ROS generation and extracellular $\mathrm{Mg}^{2+}$ concentration, is acting as a mediator of extracellular $\mathrm{Ca}^{2+}$ entry in RANKL-induced osteoclastogenesis. Based on our results, adjusting the activities of TRPM7 by genetic modification and $\mathrm{Mg}^{2+}$ ingestion has to be considered as a novel way to treat bone diseases.

\section{ACKNOWLEDGEMENTS}

This research was supported by the Basic Science Research Program through the National Research Foundation of Korea (NRF) funded by the Ministry of Education, Science and Technology (MEST) (2012R1A2A1A01003487, 2012-00 00802).

\section{REFERENCES}

1. Berridge MJ, Bootman MD, Roderick HL. Calcium signalling: dynamics, homeostasis and remodelling. Nat Rev Mol Cell Biol. 2003;4:517-529.

2. Nilius B, Owsianik G, Voets T, Peters JA. Transient receptor potential cation channels in disease. Physiol Rev. 2007;87: 165-217.

3. McNulty S, Fonfria E. The role of TRPM channels in cell death. Pflugers Arch. 2005;451:235-242.

4. Kraft R, Harteneck C. The mammalian melastatin-related transient receptor potential cation channels: an overview. Pflugers Arch. 2005;451:204-211.

5. Clark K, Middelbeek J, Lasonder E, Dulyaninova NG, Morrice NA, Ryazanov AG, Bresnick AR, Figdor CG, van Leeuwen FN. TRPM7 regulates myosin IIA filament stability and protein localization by heavy chain phosphorylation. J Mol Biol. 2008; 378:790-803.

6. Dorovkov MV, Ryazanov AG. Phosphorylation of annexin I by TRPM7 channel-kinase. J Biol Chem. 2004;279:50643-50646.

7. Boesmans W, Owsianik G, Tack J, Voets T, Vanden Berghe P. TRP channels in neurogastroenterology: opportunities for therapeutic intervention. Br J Pharmacol. 2011;162:18-37.

8. Paravicini TM, Chubanov V, Gudermann T. TRPM7: a unique channel involved in magnesium homeostasis. Int $J$ Biochem Cell Biol. 2012;44:1381-1384.

9. Kim MS, Yang YM, Son A, Tian YS, Lee SI, Kang SW, Muallem S, Shin DM. RANKL-mediated reactive oxygen species pathway that induces long lasting $\mathrm{Ca}^{2+}$ oscillations essential for osteoclastogenesis. J Biol Chem. 2010;285:6913-6921.

10. Yang YM, Kim MS, Son A, Hong JH, Kim KH, Seo JT, Lee SI, Shin DM. Alteration of RANKL-induced osteoclastogenesis in primary cultured osteoclasts from SERCA2 ${ }^{+/-}$mice. J Bone Miner Res. 2009;24:1763-1769.

11. Takayanagi H, Kim S, Koga T, Nishina H, Isshiki M, Yoshida H, Saiura A, Isobe M, Yokochi T, Inoue J, Wagner EF, Mak TW, Kodama T, Taniguchi T. Induction and activation of the 
transcription factor NFATc1 (NFAT2) integrate RANKL signaling in terminal differentiation of osteoclasts. Dev Cell. 2002;3: 889-901.

12. Aarts M, Iihara K, Wei WL, Xiong ZG, Arundine M, Cerwinski W, MacDonald JF, Tymianski M. A key role for TRPM7 channels in anoxic neuronal death. Cell. 2003;115:863-877.

13. Su LT, Chen HC, González-Pagán O, Overton JD, Xie J, Yue L, Runnels LW. TRPM7 activates m-calpain by stress-dependent stimulation of p38 MAPK and c-Jun N-terminal kinase. J Mol Biol. 2010;396:858-869.

14. Son A, Kim MS, Jo H, Byun HM, Shin DM. Effects of inositol 1,4,5-triphosphate on osteoclast differentiation in RANKLinduced osteoclastogenesis. Korean J Physiol Pharmacol. 2012; 16:31-36.

15. Park S, Lee SI, Shin DM. Role of regulators of g-protein signaling 4 in ca signaling in mouse pancreatic acinar cells. Korean J Physiol Pharmacol. 2011;15:383-388.

16. Demeuse P, Penner R, Fleig A. TRPM7 channel is regulated by magnesium nucleotides via its kinase domain. $J$ Gen
Physiol. 2006;127:421-434.

17. Abed E, Moreau R. Importance of melastatin-like transient receptor potential 7 and cations (magnesium, calcium) in human osteoblast-like cell proliferation. Cell Prolif. 2007;40:849-865.

18. Kim BJ, Lim HH, Yang DK, Jun JY, Chang IY, Park CS, So I, Stanfield PR, Kim KW. Melastatin-type transient receptor potential channel 7 is required for intestinal pacemaking activity. Gastroenterology. 2005;129:1504-1517.

19. Yu WG, Sokabe M. Hypotonically induced whole-cell currents in A6 cells: relationship with cell volume and cytoplasmic $\mathrm{Ca}^{2+}$. Jpn J Physiol. 1997;47:553-565.

20. Jans D, De Weer P, Srinivas SP, Larivière E, Simaels J, Van Driessche W. $\mathrm{Mg}^{2+}$-sensitive non-capacitative basolateral $\mathrm{Ca}^{2+}$ entry secondary to cell swelling in the polarized renal A6 epithelium. J Physiol. 2002;541:91-101.

21. Boyle WJ, Simonet WS, Lacey DL. Osteoclast differentiation and activation. Nature. 2003;423:337-342.

22. Runnels LW, Yue L, Clapham DE. The TRPM7 channel is inactivated by PIP(2) hydrolysis. Nat Cell Biol. 2002;4:329-336. 